\section{Por uma identidade} nacional "moderna"

e "regenerada": a teoria psicanalítica na Liga Brasileira de Higiene Mental (1926)

\section{Rafael Dias de Castro [*]}

[*]Professor adjunto da área de Teoria e Metodologia da História, Departamento de História/Universidade Estadual de Montes Claros (Unimontes); professor permanente do Programa de Pós-graduação em História/Unimontes. Montes Claros (MG), Brasil. rafael.castro@unimontes.br

ORCID: https://orcid.org/0000-0003-3101-3253
Resumo: $\mathrm{O}$ artigo analisa como a teoria psicanalítica foi apropriada por médicos psiquiatras nas primeiras décadas do século XX, inserida num amplo contexto de discussão de projetos para a nação brasileira. Num segundo momento, tomamos o ano de 1926 como um marco importante porque foi quando se criou a Clínica de Psicanálise e seções de estudo sobre tal saber dentro da Liga Brasileira de Higiene Mental, proporcionando um local institucionalizado de discussão e aplicação dessa teoria. Por fim, concluímos com uma breve discussão sobre os caminhos que tal teoria assumiria nos anos posteriores.

Palavras-chave: História da psicanálise; Identidade nacional; Apropriação.

For a "modern" and "regenerated" national identity: psychoanalytic theory in the Brazilian League of Mental Hygiene (1926)

\begin{abstract}
The article analyzes how psychoanalytic theory was appropriated by psychiatrists in the first decades of the 20th century, inserted in a broad context of discussion of projects for the Brazilian nation. In a second moment, we took the year 1926 as an important milestone because it was when the Psychoanalysis Clinic was created, as well as study sections on such knowledge within the Liga Brasileira de Higiene Mental, providing an institutionalized place for discussion and application of such theory. We conclude with a brief discussion on the ways that such theory would take in further years.
\end{abstract}

Keywords: History of psychoanalysis; National identity; Appropriation. 
$\mathrm{O}$ s estudos sobre a história da recepção e apropriação da psicanálise em solo latinoamericano se difundiram e se consolidaram nas últimas décadas através de narrativas que ressaltaram sua apropriação na ciência médica e em vanguardas artísticas, em histórias nacionais e transnacionais, em discussões amplas acerca da recepção de ciências instituídas no mundo europeu e sua assimilação em países tradicionalmente considerados na periferia da modernidade. ${ }^{1}$ No que diz respeito ao Brasil, compreendemos tal circulação sob a perspectiva de que textos científicos e suas apropriações ocorreram por razões e interesses intelectuais que são muitas vezes sociais e peculiares ao campo da ciência. Sendo assim, ao acompanhar tais leituras, percebemos que a recepção e apropriação desse saber carregavam um caráter de expectativa ligado a uma falta, uma lacuna, uma busca por elementos teóricos que balizassem determinado discurso médico (Dagfal, 2004).

Neste caminho, a proposta de Hans Ulrich Gumbrecht (2001) auxilia no entendimento dos aspectos sociais e culturais, tanto da produção do texto pelo autor como de seu ambiente de recepção e apropriação. De acordo com Gumbrecht, para se apreender a recepção e as condições de diferentes constituições de sentido sobre determinado texto deve-se ter como foco as interações entre o autor, os leitores e a reconstrução do contexto sócio-histórico que possibilita tais interações, considerando, por exemplo, quando o texto foi produzido, quando o texto foi recebido, que posições sociais ocupavam os interlocutores, a que servia o texto como meio. Assim, metodologicamente, a função de cada texto precisa ser determinada "como alteração do conhecimento de seus receptores, intencionada pelo autor (função intencionada); como alterações buscadas e realizadas pelos receptores quanto a seu próprio conhecimento (necessidade/função realizada)" (Gumbrecht, 2001, p. 179).

Esse aparato teórico possibilita dar respostas à análise sobre o conhecimento prévio dos leitores, permitindo o entendimento da reorganização de suas ideias às suas diferentes expectativas (sejam elas sociais, culturais e/ou políticas). Ressalte-se que a adoção de modelos institucionais gestados em outras realidades (particularmente a europeia), revela não a inferioridade ou a tendência imitativa local, mas um processo ativo que também adapta e, em muitos casos, tinge com cores próprias tais conhecimentos. Conforme Kapil Raj (2007, p. 155), os enunciados, objetos e práticas científicas só se deslocam do seu lugar de invenção, só se universalizam, à custa de acomodações que reconfiguram os procedimentos científicos no corpo social em que se inserem: "exportar os produtos da ciência para fora do seu lugar de concepção ou de fabricação exige a réplica dos instrumentos, saber fazer, protocolos, regras e convenções sociais e morais..., ou a recomposição do equilíbrio entre todos estes elementos". Em outras palavras, tal perspectiva analítica busca valorizar a força e a autono-

'Conferir, dentre outros: Glick (1999); Russo (2000); Facchinetti (2001); Plotkin (2009); Castro (2015); Ruperthuz (2017). 
mia (históricas, sociais, culturais) dos contextos locais de recepção e apropriação por parte de seus atores.

Portanto, o objetivo deste artigo é analisar a apropriação e a institucionalização da psicanálise pela psiquiatria no Rio de Janeiro no início do século XX, especificamente na Liga Brasileira de Higiene Mental, no ano de 1926. Nesta cidade, a psicanálise circulava intensamente dentro do Hospital Psiquiátrico e nas sociedades específicas do campo psiquiátrico (como na Sociedade de Neurologia, Psiquiatria e Medicina Legal e a própria Liga). Foi no cenário carioca, através de importantes nomes da psiquiatria, que a psicanálise pôde se inserir e contribuir em diferentes campos do conhecimento, como o da educação e o da criminologia, sendo apropriada também com o intuito de interpretação da sociedade e para a modificação de sua estrutura social e cultural (Castro, 2015).

Nas décadas de 1920 e 1930, os discursos médicos psiquiátricos que se fundamentavam em pressupostos psicanalíticos tentavam dar conta de detectar e educar o primitivismo do brasileiro (o 'id' nacional), com o intuito de ajustar seus valores e comportamentos aos ideais do mundo moderno e civilizado. A psicanálise auxiliava a psiquiatria na construção de uma identidade nacional marcada pela regeneração e modernização. O que havia sido anteriormente lido como advindo de raças primitivas incapazes de produzir uma civilização, era agora compreendido como advindo de indivíduos a quem se deveria disciplinar por meio de um trabalho educativo, sendo que o papel da psiquiatria seria fazê-los desviar seus impulsos na direção de fins mais elevados: se o brasileiro (caracterizado pelos excessos e desvios) era primitivo, caberia introduzir, a partir das ferramentas psicanalíticas, a possibilidade de educá-lo (Castro, 2015).

Assim sendo, mostraremos como a recepção e a apropriação da teoria psicanalítica pelos psiquiatras foi inserida num amplo contexto de discussão de projetos para a nação brasileira. Num segundo momento, tomamos o ano de 1926 como um marco importante porque foi quando se criou a Clínica de Psicanálise e seções de estudo sobre tal saber dentro da Liga Brasileira de Higiene Mental, proporcionando um local institucionalizado de discussão e aplicação dessa teoria. Por fim, concluímos com uma breve discussão sobre os caminhos que tal teoria assumiria nos anos posteriores.

\section{A teoria psicanalítica no contexto de discussão de projetos para a nação brasileira}

Em fins do século XIX e início do XX, juntamente a teorias raciais e diferentes determinismos - como o climático e o geográfico -, a relação litoral-interior/sertão, cidade-campo, tornaram-se importantes fatores para a intelectualidade da época interpretar a configuração 
da sociedade brasileira. De acordo com Heloísa Starling (2008), o caso específico da palavra 'sertão' revela uma maneira peculiar de narrar o projeto da fundação nacional a partir dos confins, das margens em que se refletem e se cruzam dúvidas sobre os dilemas da nossa formação histórica e social: "de um lado, sertão indica o processo de formação de um espaço interno, a perspectiva do interior; de outro, sertão traduz a configuração de uma realidade política: a condição do desterro, a ausência de leis, a precariedade dos direitos, a inexistência da ordem" (p. 134).

No livro Um sertão chamado Brasil (1999), Nísia Lima discute o sentido atribuído, no pensamento social brasileiro, à relação entre litoral e interior. Através de relatos sobre o "sertão" resultantes de viagens científicas, expedições militares e incursões ao interior, a autora destaca que essas diferentes interpretações sobre o Brasil se articulavam em torno do debate da incorporação dos sertões à unidade nacional. Quando, a partir do final do século XIX, começavam a se pensar maneiras de redimir o sertão do atraso e integrá-lo à moderna sociedade, a ideia da distância em relação ao poder público e a projetos modernizadores passava a ser pensada como a que melhor caracterizava esse ambiente. Interpretada como uma região abandonada, o destaque conferido à necessidade de se cuidar dos sertões brasileiros acarretava em diversos projetos, como os de delimitação de fronteiras e de integração econômica e política desse interior com o litoral do Brasil (Lima, 1999, p. 60). Nesse contexto, surgiam também ideias sobre o saneamento dos sertões, convocado por cientistas que mapeavam as doenças existentes e se preocupavam em salvar os "valores nacionais" encontrados no interior do país. Segundo Lima, o sertão, nessa perspectiva, foi concebido como um dos polos do "dualismo que contrapõe o atraso ao moderno, e é analisado como o espaço dominado pela natureza e pela barbárie. No outro polo, litoral não significa simplesmente a faixa de terra junto ao mar, mas principalmente o espaço da civilização" (Lima, 1999, p. 62-64).

Entretanto, nesse mesmo momento de "descobrimento dos sertões", a conclusão era a de que mesmo a capital federal, centro político, cultural e comercial da nação, no início do século XX, tinha um perfil de uma cidade insalubre e mal provida de serviços urbanos básicos (Benchimol, 1992, p. 17-20). Somente a partir da presidência de Rodrigues Alves (19021906) tal situação se transformaria. Com o intuito de fazer da cidade do Rio de Janeiro uma vitrine para a captação dos interesses estrangeiros, concebia-se um plano em três direções: a modernização do porto ficaria a cargo do engenheiro Lauro Muller (1863-1926), o saneamento da cidade seria responsabilidade do médico sanitarista Oswaldo Cruz (1872-1917) e a reforma urbana ficaria a cargo do engenheiro Pereira Passos (1836-1913), também nomeado prefeito da cidade (Benchimol, 1992). ${ }^{2}$

${ }^{2}$ Benchimol chama atenção para um aspecto contraditório da relação entre esses personagens, que habitualmente são encarados como "faces de uma mesma moeda". Cf:. Benchimol (2000, p. 275-276). 
É essa a época da intensa reforma urbana efetuada por Pereira Passos: alargamento e extensão de ruas e avenidas e o plano de remodelação da cidade, incluindo aí a demolição de prédios e casas (Benchimol, 1992, p. 235-237). Segundo Jeff Garmany e Matthew Richmond (2020), o planejamento urbano no Brasil tornava-se interconectado com a ciência médica desde o início do século XX, quando bacteriologistas, epidemiologistas e especialistas em saúde pública assumiam a liderança nas políticas de habitação e desenvolvimento urbano. Como exemplo, os autores comparam a adoção do higienismo no Brasil a sua forma seguida em espaços na Europa do mesmo período: "whereas in Europe it was driven by concerns over public well-being, sanitation and social morality, in Brazil it became a means to defend civilisation against backwards, infectious, unproductive, and dangerous racialised masses" (Garmany, Richmond, 2020, p. 128).

Esta foi, no Brasil, a época das grandes vacinações, que passavam a ser ministradas em nome do bem geral da nação, a despeito das tensões que essa prática acabava gerando. Tais campanhas transformavam-se em medidas cada vez mais impopulares, sendo que o processo de desapropriação de imóveis e despejo dos proprietários (para alargamento de ruas e avenidas), aliado à instauração da vacinação obrigatória liderada por Oswaldo Cruz, acabava por originar a Revolta da Vacina em 1904 (Sevcenko, 1984), talvez a insurreição mais conhecida desse contexto. Entretanto, mesmo diante de grandes tensões, ao final da primeira gestão de Oswaldo Cruz na saúde pública, em 1906, a cidade do Rio de Janeiro havia se transformado.

Tal movimento apresentava um ímpeto considerável em certas regiões do país. No ano de 1918, por exemplo, o governo organizava o Serviço de Profilaxia Rural no Brasil, criando os primeiros postos nos estados de Minas Gerais, Maranhão e Paraná, através de parcerias com os próprios estados. Liane Bertucci destaca que no Paraná a organização dos postos primeiro se deu no intuito de "medicar e vacinar, sanear e educar [...]. Era preciso tanto difundir práticas higiênicas - tais como lavar as mãos antes de comer - quanto distribuir remédios e realizar medidas sanitárias, como drenar o solo e construir fossas sépticas" (Bertucci, 2019, p. 60). Entretanto, de acordo com Luiz de Castro Santos, na década de 1910 as políticas públicas na área de saúde ainda se limitavam às capitais e demais centros urbanos de importância. O interior do país, particularmente o "sertão", permanecia esquecido (Castro-Santos, 1985, p. 193). Em 1916, ano de publicação dos seus cadernos de viagem por vários estados do Nordeste e Goiás, os médicos Artur Neiva e Belisário Pena reafirmavam, com direito a fotos e descrições físicas, as péssimas condições de vida no interior do país. A partir da publicação do Relatório Neiva-Pena, o movimento sanitarista superava sua fase urbana, com a nova bandeira do saneamento dos sertões (Castro-Santos, 1985, p. 199-200). ${ }^{3}$

${ }^{3}$ A referida missão do Instituto Oswaldo Cruz foi realizada no ano de 1912. 
A constatação da necessidade de saneamento dos sertões veio acompanhada de um processo de transformação das formas de se pensar o Brasil. De fato, é nesse período que podemos observar o crescimento de uma consciência entre as elites em relação aos graves problemas sanitários do país e de um sentimento geral de que o Estado nacional deveria assumir mais a responsabilidade pela saúde da população e salubridade do território (Hochman, 1998, p. 40). É nesse contexto que a obra de Euclides da Cunha é retomada como um marco de referência para os intelectuais que direcionavam seus cuidados para os sertões. Ao tema do isolamento do sertanejo, sugerido por Cunha, esses sanitaristas passavam a associar o do abandono, responsabilizando enfaticamente as elites intelectuais e políticas por tal situação (Hochman, 1998, p. 79).

De acordo com Gilberto Hochman, a doença passava a ser identificada como um dos principais laços constituintes da sociedade brasileira durante a Primeira República, sendo tal interpretação difundida e compartilhada cada vez mais por segmentos importantes das elites. Esse movimento sanitarista impregnava a sociedade com uma interpretação sobre o Brasil a partir de dois eixos complementares, que o definiam: o hospital e os sertões. O hospital indicava a presença da doença e sua difusão, e os sertões significavam o abandono e a ausência da autoridade pública: "dessa lógica, o desenvolvimento da consciência de transmissibilidade da doença geraria proposições que almejavam a inversão da caracterização do Brasil: presença da autoridade pública, ausência de doenças" (Hochman, 1998, p. 79). ${ }^{4}$

Estudo realizado por Nísia Lima e Gilberto Hochman demonstra que a campanha pelo saneamento sensibilizava progressivamente nomes expressivos das elites intelectuais e políticas do país, tendo como um dos marcos mais significativos a criação da Liga Pró-Saneamento do Brasil, em fevereiro de 1918 (Lima, Hochman, 1996, p. 26). Os autores mostram, ainda, que os médicos que aderiam à campanha do saneamento rural refutavam as relações entre as doenças cujo combate priorizavam (malária, ancilostomíase e doença de Chagas) e a origem racial da população (Lima, Hochman, 1996, p. 31). Enfaticamente, argumentavam que todos podiam contrair a doença, que não respeitava limites de raça ou condição social (p. 23).5

Além disso, conforme Rafael Almeida (2017), o poder público asseverava ser preciso educar os sentidos das "classes incultas" para que melhor se protegessem contra o mal e auxiliassem na regeneração da população brasileira, prioridade para todos aqueles que almejavam "o progresso". Segundo o autor, ao mesmo tempo em que rumam em direção às terras "sem governo" dos sertões para descobrir um povo isolado e enfermo, os médicos

\footnotetext{
${ }^{4}$ O médico Miguel Pereira (1871-1918) declarou, em discurso proferido em outubro de 1916, ser o Brasil "um imenso hospital”, devido às condições sanitárias e epidemiológicas de sua população no interior do país. Cf.: Sá (2009).

${ }^{5}$ Importante frisar que as relações entre medicina, saúde pública e as questões raciais da população brasileira não se encerram com essa visão sobre a ausência do poder público e seu impacto na saúde da população. Para conferir debate específico sobre tais relações, ver Maio; Santos (2010).
} 
sanitaristas "voltam seus olhares à cidade e percebem que esse Brasil, isolado e doente, nunca estivera tão longe. Nos morros do Rio encontram as cafuas do sertão, a vida rural, a roça, as galinhas e porcos e, também, a gente mestiça, doente, ignorante e bárbara do interior do país" (Almeida, 2017, p. 12). Lima e Hochman mostram que o diagnóstico de um povo doente significava que, em lugar da resignação, da condenação ao atraso eterno, seria possível recuperá-lo, por meio de ações de higiene e saneamento, fundadas no conhecimento médico e implementadas pelas autoridades públicas (Lima, Hochman, 2000, p. 501). A ciência, em especial a medicina, propiciava um alívio para intelectuais que até então não enxergavam alternativas para um país que parecia condenado, dada sua composição racial.

Para exemplificar tal mudança de perspectiva, um fato muito citado pela historiografia é o "Jeca Tatu", de Monteiro Lobato: enquanto mestiço, pobre e ignorante, de certa forma representava a condição vivenciada pela maioria da população brasileira (Almeida, 2017, p. 11). Em 1918, porém, em O problema vital, Lobato parecia ter mudado de posição, quando, desviando a atenção do problema racial, apresentava "Jeca Tatu" não como o resultado de uma formação híbrida, mas como o fruto de doenças epidêmicas. A figura do "Jeca Tatu" parecia se revestir, assim, de novos significados, comprovar a falência do argumento da degeneração racial e a importância de uma educação sanitarista: "o Jeca não é assim, ele está assim!"(Lima, Hochman, 1996, p. 23). ${ }^{6}$

Especificamente no campo da ciência psiquiátrica, na passagem do século XIX para o XX no Brasil, observa-se também a repercussão de determinadas teorias alienistas que relacionavam os conceitos de raça, mestiçagem, degenerescência e alienação mental. O médico Raimundo Nina Rodrigues (1862-1906), professor de Medicina Legal da Faculdade de Medicina da Bahia, por exemplo, defendia a existência de particularidades nos negros e nos mestiços brasileiros, com relação a sua psicopatologia e a sua imputabilidade penal. Esse autor considerava que os negros e miscigenados brasileiros eram idênticos aos povos primitivos identificados pelo psiquiatra francês Valentin Magnan (1835-1916), determinando assim a degeneração da "raça nacional": não era possível fazer com que essa população primitiva se desenvolvesse (Oda, 2003). Nesses discursos, se ressaltava a presença de um vínculo entre a raça e a doença mental, com fortes dimensões políticas e sociais assumidas pelo saber e pela prática alienista na sociedade brasileira das últimas décadas do século XIX. Não à toa, algumas correntes da intelectualidade local, por exemplo, pretendiam eliminar gradualmente a herança das raças africanas da sociedade, ressaltando que o principal pro-

\footnotetext{
${ }^{6}$ Exemplo do movimento intelectual na elaboração de imagens identitárias sobre o país e seu interior pode ser visto também no Manifesto regionalista de 1926, de Gilberto Freyre, ou nos escritos de Oliveira Vianna (como Populações meridionais do Brasil, de 1920), que contrastam sobre o "caráter nacional" estar no modo de vida dos senhores de engenho do Nordeste (como apontava Freyre) ou nas famílias fazendeiras de Minas Gerais (como dizia Vianna). Sobre tal debate, conferir segunda parte de Bresciani (2007).
} 
blema da nacionalidade era um povo que deveria ser paulatinamente substituído através da imigração (Venancio, Facchinetti, 2005, p. 359).

Entretanto, a tese racialista começava a dar sinais de enfraquecimento frente às exigências experimentalistas das ciências biomédicas. A força-tarefa idealizada por Rodrigues Alves para reformar o Distrito Federal de modo a torná-lo moderno e higiênico incluía não apenas mudanças físicas na cidade, mas arregimentava diversos médicos identificados com os trabalhos experimentais e laboratoriais de Louis Pasteur (1822-1895) e Robert Koch (1843-1910) para sanar as epidemias que se alastravam pela cidade (Benchimol, 1992). Acompanhando o deslocamento do eixo médico mais amplo, ${ }^{7}$ uma parcela dos psiquiatras passava a questionar o conceito racialista da degeneração, buscando novas "soluções" para o tratamento dos doentes e abrindo-se para a busca de uma profilaxia contra a doença mental. Era neste contexto das reformas implementadas por Rodrigues Alves que José Joaquim Seabra (1855-1942), então ministro da pasta da Justiça e Negócios Interiores do governo, nomeava o jovem médico baiano Juliano Moreira (1873-1932) para a direção do Hospício Nacional, para comandar e auxiliar na reorganização da Assistência a Alienados do Distrito Federal (Brasil, 22 dez. 1903).

Juliano Moreira obteve reconhecimento como aquele que poderia reforçar as iniciativas "modernizadoras" do Estado e ampliar os esforços regeneradores para a assistência pública aos alienados. ${ }^{8}$ Entre 1895 e 1902, Moreira foi à Europa algumas vezes, visitando hospitais, colônias e laboratórios e participando de reuniões científicas e cursos. De volta ao país, visitava as instituições psiquiátricas dos estados brasileiros, publicando um panorama da medicina geral e da psiquiatria nacional entre os anos de 1901 e 1902 na Gazeta Médica da Bahia (Facchinetti, Castro, 2015). Nesses artigos, Juliano Moreira destacava que havia um único hospital com laboratório em todo o país e fez um libelo pela ciência experimental, por instituições equipadas com "máquinas do trabalho científico", os laboratórios experimentais, e a favor do ensino médico articulado à pesquisa clínica (Facchinetti, Castro, 2015).

Assim, além de convir para contornar os impasses políticos internos entre os médicos do hospício e os da Faculdade de Medicina por meio da nomeação de um médico baiano, fora do epicentro das disputas científicas e políticas do Rio de Janeiro (Engel, 2001, p. 255257), a indicação adveio da posição científica de Juliano Moreira se afinar com o novo modelo de Estado que se firmava. Após ser nomeado, em 1903, para a direção do Hospício

\footnotetext{
${ }^{7}$ A Faculdade de Medicina havia sofrido substantivas reformas educacionais no fim do século XIX. Estas introduziam o ensino prático nas disciplinas médicas e deram lugar à medicina experimental sob inspiração do modelo germânico (Edler, 1996, p. 284-285).

${ }^{8}$ Sobre fatores apontados como influentes na escolha de Juliano Moreira ao cargo, conferir Engel (2001, p. 240-245).
} 
Nacional de Alienados, ele se tornava, posteriormente, diretor-geral de Assistência a Alienados (1911-1930).

No ano de 1904, com a nomeação do professor Henrique Roxo (1877-1969) para ocupar a cátedra de psiquiatria na Faculdade de Medicina do Rio de Janeiro, a direção do hospício deixava de ser exercida pelo professor catedrático de psiquiatria. Ao ser desfeita a unidade da academia com a assistência pública, a ciência psiquiátrica que se sobressaía não era a gerada no espaço acadêmico, mas sim a capitaneada por Moreira do interior do asilo e das sociedades de tipo científico e filantrópico: "nesses espaços se formou toda uma escola inspirada na psiquiatria alemã de Emil Kraepelin e propagada por Juliano Moreira” (Venancio, 2003, p. 890). Portanto, se adotava como orientação a corrente alemã de psiquiatria ${ }^{9}$ com Kraepelin, que divergia da vertente francesa tradicionalmente adotada no Brasil (Facchinetti, Muñoz, 2013, p. 246). Com o apoio do organicismo, a ciência psiquiátrica sob a batuta de Moreira passava a privilegiar e consolidar o interesse pelas relações causais entre distúrbios somáticos e consequências mentais, procurando sistematizar as entidades mórbidas mentais, a exemplo das orgânicas, para efeito das classificações nosográficas. ${ }^{10} \mathrm{~A}$ partir da sua entrada no Hospício, o embasamento teórico e terapêutico começavam a ser debatidos sob novos parâmetros, levando a práticas consideradas como de maior cientificidade, o que, por sua vez, determinava a inserção dessas no sistema de assistência ao alienado. Com o apoio do organicismo, Moreira há um só tempo lutava por desacreditar as teses racialistas (Moreira, 1905) e climáticas (Moreira, Peixoto, 1906) como base etiológica da doença mental e reafirmava a ciência como fundamental para a regeneração dos cidadãos (Moreira, 1922).

Em suma, em contraposição à tese de Nina Rodrigues e às teses do branqueamento da população, o psiquiatra Juliano Moreira enfatizava a não relação entre raça, degenerescência e psicopatologia. Em outras palavras, ele se contrapunha a Nina Rodrigues quanto à crença na inferioridade mental inata do negro e no efeito negativo da mestiçagem para o caráter físico e mental dos brasileiros (Oda, 2003). Assim, Moreira defendia que, em parte, a origem das doenças mentais devia-se a fatores físicos e situacionais, como a falta de higiene e falta de acesso à educação, contrariando o pensamento racialista em voga (Moreira, 1922).

Paulatinamente, ele e o grupo por ele formado em seu entorno garantiam a hegemonia da psiquiatria alemã organicista. Afinado a esse discurso e articulado ao movimento sani-

\footnotetext{
${ }^{9}$ A aproximação de médicos alemães e brasileiros fez parte de um processo de internacionalização das ciências e da medicina brasileira e alemã. No que se refere à psiquiatria do Brasil, Juliano Moreira foi fundamental para esse processo de internacionalização, bem como para a circulação das diferentes teorias de língua alemã (Facchinetti, Castro, 2015).

${ }^{10}$ A teoria de Kraepelin, por exemplo, tinha como interesse validar, a partir de dados estatísticos, as classificações nosográficas das enfermidades mentais, lançando mão de argumentos comparativos para comprovar que os quadros patológicos existiam em todas as regiões e não apenas nos centros urbanos (Facchinetti, Muñoz, 2013).
} 
tarista, que firmava a tese de que a degeneração era decorrente da falta de saúde e educação da população, bem como às redes científicas internacionais, o discurso da profilaxia também passava a ganhar cada vez mais espaço na psiquiatria, especialmente a partir da década de 1920 (Boarini, 2003). Assim, a superação do obstáculo racial e o deslocamento das preocupações para deveres do Estado ampliava as funções da psiquiatria local, que deixava de apenas tratar dos doentes mentais, marcados inexoravelmente por suas "taras degenerativas", para uma nova missão, a de evitar que as pessoas normais fossem degeneradas pelo meio insalubre física ou psiquicamente (Reis, 1994). Foi a partir deste deslocamento que surgia, por exemplo, a Sociedade de Eugenia (1918), bem como a Liga Brasileira de Higiene Mental (1923). Passava a ser corresponsabilidade dos médicos psiquiatras não apenas o controle, mas a cura e o desaparecimento de vagabundos, prostitutas, alcoólatras, enfim, daqueles que não se encaixavam no projeto idealizado do brasileiro moderno-saudável e que podiam atrasar a modernização do país (Facchinetti, 2001).

Por conta de tal ampliação, crescia também a busca por diferentes direções teóricas que pudessem contribuir para acelerar o progresso do país, permitindo que adentrássemos no patamar das nações civilizadas. Incorporado aos projetos de nação e empenhados na construção do "brasileiro ideal", um grupo de psiquiatras buscava na psicanálise respostas para auxiliar nesse processo (Castro, 2015). Se os médicos sanitaristas haviam demonstrado que o sertão estava abandonado e era possível modernizá-lo, a psiquiatria, a partir dos pressupostos psicanalíticos, apontava a necessidade de se pensar não somente a entrada concreta, via saneamento, nos sertões; tampouco apenas no nível comportamental da higiene mental no processo de disciplina e ordem das cidades, mas também a entrada profunda e de internalização na direção do 'id brasileiro' (primitivo e resistente ao progresso) com vistas a sua transformação em um 'ego civilizado'.

\section{A Liga Brasileira de Higiene Mental}

Como vimos, os psiquiatras brasileiros do início do século XX, sob a batuta do diretor do Hospício Nacional e diretor da Assistência aos Alienados, Juliano Moreira, passavam a afirmar que sanear o país e educar sua população seriam soluções para ultrapassar os problemas nacionais. Afinado a esse discurso e à ideia de que a doença advinha em grande medida da falta de saúde e educação, uma nova resposta da psiquiatria aos problemas que obstruíam a modernização do país e as consequentes soluções para a população brasileira passavam a ser discutidas também a partir do discurso da higiene mental (Boarini, 2003).

A origem do movimento de higiene mental pode ser atribuída ao trabalho de Clifford Beers (1876-1943), que em 1908 publicou um livro baseado em sua própria experiência como interno de três hospícios dos Estados Unidos (Bertolote, 2008). Com a repercussão do livro, 
em 1909 se fundou o Comitê Nacional de Higiene Mental que, em suas origens, pretendia refletir, a partir da experiência de Beers, sobre a necessidade de dar maior atenção aos pacientes com transtornos mentais dentro de tais instituições: "Quando em 1909 se organizou o Comitê, seu trabalho principal residia em humanizar a atenção aos loucos: erradicar os abusos, as brutalidades e tanto sofrimento causados a eles" (Beers apud Bertolote, 2008, p. 113). A partir de 1919, com a internacionalização das atividades da Comissão, começavam a surgir alguns estabelecimentos nacionais (p. 113).

No Brasil, em 1923, o médico e psiquiatra Gustavo Riedel (1887-1934) fundava a Liga Brasileira de Higiene Mental, com sede no Rio de Janeiro. Conforme aponta Vanderlei de Souza, a intenção de Riedel em criar a Liga surgia após seu retorno do Congresso Médico Latino-americano realizado em Havana (Cuba), em 1922. Segundo Souza, o interesse inicial deste médico-psiquiatra era "fundar uma instituição de medicina social com o intuito de aprofundar as discussões sobre profilaxia mental que já vinham sendo debatidas no Rio de Janeiro" (Souza, 2006, p 42). Contudo, a pesquisadora Priscila Cupello mostra que a Liga Brasileira de Higiene Mental rapidamente passava a abarcar um discurso profilático mais específico (Cupello, 2013, p. 78-80). Se inicialmente o objetivo da Liga parecia ser o de melhorar a assistência aos alienados nas instituições psiquiátricas brasileiras, a partir de 1926 seus objetivos mudavam, passando a almejar a prevenção eugênica e a educação higiênica, assumindo questões advindas do campo da prevenção (Cupello, 2013, p. 41).

Dessa maneira, com a ampliação das funções da psiquiatria local e com a promulgação da nova lei de Assistência aos Psicopatas em 1927," deixava-se de apenas tratar dos doentes mentais, marcados inexoravelmente por suas "taras degenerativas”, para uma nova missão, a de evitar que as pessoas normais fossem degeneradas pelo meio insalubre física ou psiquicamente, ampliando também o poder da psiquiatria, bem como multiplicando suas tarefas (Facchinetti, 2001, p. 152). Diante de tais mudanças, os médicos psiquiatras da Liga passavam a assumir como suas responsabilidades não apenas o controle, mas a cura e o desaparecimento de vagabundos, prostitutas, alcoólatras (Venancio; Facchinetti, 2005). Também a infância e a maternidade passavam a ser compreendidas por esses atores como centrais para o futuro da nação e, como tal, também se tornavam objeto de atenção e cuidado (Castro, 2016).

Em seus estatutos, a Liga definia como principais funções, por exemplo, a prevenção das doenças nervosas e mentais pela "observância da higiene geral e especial do sistema nervoso; realização de um programa de Higiene Mental e Eugenética no domínio das atividades individual, escolar, profissional e social" (Estatutos, 1925, p. 223). Assim, passava-se a com-

${ }^{11}$ O decreto de 1927 dispôs sobre profilaxia e higiene, e fez com que os alienistas passassem a ser chamados oficialmente de psiquiatras. Além disso, definia que a Assistência deveria abranger não apenas os alienados, mas todos aqueles em risco de sofrer de desordens mentais (Brasil, 10 jan. 1927). 
bater as causas das doenças mentais e nervosas, se reafirmava a importância da assistência aos doentes mentais e, principalmente, a necessidade de atenção aos predispostos a psicopatias, com finalidade profilática.

Nesses discursos, a higiene mental e a eugenia surgiam apropriadas muitas vezes como sinônimas, afirmando que para higienizar o país eram necessárias várias medidas eugênicas, guiadas pela psiquiatria local (Boarini, 2003). Conforme ressalta Vanderlei de Souza, mesmo que tenham, eventualmente, acionado um projeto de regeneração racial, na maioria dos discursos os higienistas/eugenistas procuravam criar um modelo de eugenia pelo qual fosse possível pensar as diferenças entre as raças sem que isso excluísse o "valor eugênico" da mestiçagem nacional e, ao mesmo tempo, a viabilidade do Brasil como uma nação moderna e civilizada: o problema não era a "cor da raça", mas o fato da "raça brasileira" precisar ser melhorada (Souza, 2006, p. 46-48). Essa perspectiva trazia para a psiquiatria a possibilidade de instituir um projeto viável para a civilização brasileira, já que se passava a abandonar a teoria sobre o clima e a raça como fatores determinantes do insucesso da nação, trazendo para o primeiro plano a possibilidade de educar e tratar uma população abandonada pelo poder público e entregue a todos os tipos de doenças (Lima, Hochman, 1996).

Devido a essa ampliação das funções da ciência psiquiátrica, se fazia necessário buscar diferentes direções teóricas e concepções práticas que pudessem contribuir para acelerar o progresso do país, permitindo que se adentrasse no patamar das nações civilizadas. Foi dessa forma que alguns psiquiatras da Liga, incorporados aos projetos de nação e empenhados na construção do "brasileiro ideal", buscavam institucionalizar a psicanálise para que essa pudesse auxiliá-los em seus projetos. De acordo com o pesquisador José Franco Reis, a psicanálise era um dos discursos mais afinados que a Liga oferecia como uma das soluções técnicas, que exigia uma crescente ampliação do papel intervencionista do Estado. Para ele, o fato que colocava a psicanálise nesse patamar era a crença dos próprios "psicanalistas da Liga" sobre sua importância: "o discurso psicanalítico da Liga, pela voz de Porto-Carrero, é um dos mais pretensiosos. Sua crença na ciência é absoluta” (Reis, 1994, p. 237).

A pesquisadora Jane Russo mostra que o papel desse discurso médico psiquiátrico, na constituição de um projeto para a nação brasileira, apresentava duas importantes questões: a primeira, sobre a preocupação com aquilo que da nova ciência (psicanálise) poderia ser utilizado num projeto educativo ou higiênico. A outra questão era a ideia que se produzia, a partir da apropriação desse saber, um discurso que tinha um caráter moral, mas ao mesmo tempo moderno, conservador e laico (Russo, 2000, p. 13). Nesse processo, a psicanálise passava a ser utilizada como método de diagnóstico da realidade do país e terapêutica para sua evolução, por meio da educação científica, pensada como capaz de recalcar os conteúdos "anormaes" e direcionar os impulsos para objetos idealizados pela cultura, por via da sublimação (Castro, 2015). 


\section{A Clínica de Psicanálise e a seção de estudo "Psicologia aplicada e psicanálise"}

Algumas das questões tratadas por Sigmund Freud (1856-1939) em sua teoria psicanalítica já se encontravam nas preocupações dos psiquiatras cariocas, tanto nos aspectos teóricos quanto práticos, desde a década de 1910 (Castro, 2015). Os psiquiatras já haviam constatado a importância do "psiquismo na vida individual e social, tomando para si, de bom grado, a tarefa obstinada de regenerar a nacionalidade, evitar a degeneração mental da população através da higiene mental e de medidas preventivas de caráter eugênico" (Reis, 1994, p. 66). Ao refletirem a partir de uma perspectiva de intervenção no social, da criação de um projeto específico para auxiliar no "processo civilizatório" nacional, tais psiquiatras passavam a se interessar não apenas pelas discussões teóricas ou pela simples utilização da ferramenta psicanalítica para auxiliar no tratamento das doenças mentais, mas também nas possibilidades que esta oferecia para colaborar no projeto civilizatório mais amplo no qual a psiquiatria se inseria, em especial alguns membros da Liga.

É importante ressaltar que, desde sua fundação, já faziam parte da Liga importantes psiquiatras interessados na psicanálise: Juliano Moreira, Henrique Roxo e Antonio Austregésilo (1876-1960), que foram declarados "presidentes de honra". Em outubro de 1926 o Dr. Julio Porto-Carrero (1887-1937)12 (inscrito como membro da Liga), em comunicação ao Congresso Médico de Porto Alegre, afirmava já ser possível mencionar o andamento dos trabalhos sobre a psicanálise na Liga:

Em maio de 1926, o Prof. Ernani Lopes acrescentou à folha de inestimáveis serviços prestados à Liga Brasileira de Higiene Mental, de que é presidente, a instalação de um serviço de psicanálise. O gabinete, ainda rudimentar, tem por chefe, desde sua fundação, o autor dessas notas (Porto-Carrero, [1926] 1929b, p. 27).

O próprio Porto-Carrero levantava a questão sobre se a psicanálise teria aceitação, enquanto um método terapêutico, numa campanha de higiene mental:

É fácil a resposta. A psicanálise, no pesquisar os complexos recalcados que fazem os pequenos neuróticos os impulsionados para o tóxico, os tímidos, os "peculiares" de caráter, etc. - varre, por assim dizer, as fronteiras da loucura. Se atentarmos ainda em que a Liga pode influir, pela psicanálise, na educação das escolas primárias, na dos patronatos menores, na dos pequenos contraventores entregues hoje a um tribunal

${ }^{12}$ Sobre a relação de Porto-Carrero com a psicanálise, conferir Castro (2012). 
especial, veremos que já será bem larga a esfera de ação em que poderemos atuar (Porto-Carrero, [1926] 1929b, p. 27-28).

O autor admitia que a psicanálise auxiliava os psiquiatras da Liga em um projeto profilático através da educação, principalmente com as crianças, evitando assim o surgimento de futuros infratores e/ou desviantes. Além disso, ela auxiliava também no conhecimento mais amplo sobre o meio e a sociedade em que se objetivava intervir, trazendo a possibilidade de compreender a psicologia coletiva do homem brasileiro, seus "totens e tabus" (Porto-Carrero, 1933) e suas características mais peculiares: tudo isso sob uma perspectiva de um programa profilático de higiene mental.

Com o incremento da psicanálise na Liga através da implantação da Clínica, a visão que os psiquiatras-psicanalistas tinham sobre tal saber mudava consideravelmente. Conforme apontava Porto-Carrero, os "medíocres de inteligência" passavam agora a ser o alvo preferencial de intervenção e tratamento pela psicanálise:

É nossa opinião que os melhores doentes para análise são os medíocres de inteligência. Os curtos de entendimento são verdadeiras torturas para o psicanalista - as suas associações são sempre superficiais [...]. Parecia, à primeira vista, que os doentes inteligentes fossem os melhores para a psicanálise. Nem sempre. É frequente vê-los rejeitar e calar tais e tais ideias, porque não lhes pareçam úteis à análise; arvoram-se em analistas, querem interpretar a si mesmos, antes do necessário treinamento e por vezes se tornam prolixamente imaginosos, fazendo correr ao médico o risco de perder-se no mare magnum de suas associações (Porto-Carrero, [1926] 1929b, p. 28-29).

Dessa passagem, algumas questões aparecem como fundamentais. Primeiro, a perspectiva sobre os melhores "analisandos" passava por mudanças, pois o psicodiagnóstico que os psiquiatras-psicanalistas passavam a fazer acerca dos brasileiros era o de um povo medíocre e, por isso, era a grande massa a ser tratada, surgindo daí a possibilidade de fazer do tratamento pela via psicanalítica o meio mais eficaz. ${ }^{13}$ Além disso, assinalava-se a necessidade do psiquiatra-psicanalista possuir uma cultura superior a do "analisando", pois, para Porto- Carrero, as associações que o paciente viesse a fazer somente seriam compreendidas pelo médico que conseguisse associar a cadeia de imagens apontadas pelo paciente, se possuísse uma cultura superior à dele (Porto-Carrero, [1926] 1929b, p. 29).

A institucionalização da psicanálise na Liga era organizada cuidadosamente por seus responsáveis, que se preocupavam inclusive com o aspecto físico do ambiente onde funcionava o consultório. A instalação do consultório de psicanálise da Liga foi feita com a "maior

${ }^{13}$ Sobre esta discussão específica, conferir os capítulos 3 e 4 de Castro (2015). 
sobriedade, para fugir ao aspecto de consultório médico; e até os ornatos e cores foram escolhidos de maneira tal que dificilmente possam sugerir situações emotivas que se enxertem na corrente associativa" (Porto-Carrero, [1926] 1929b, p. 28-29). A preocupação não era somente estética, pois "a simples vista de uma parede rachada basta para desviar a sequência de ideias de um doente pouco afeito a abstrações” (Porto-Carrero, [1926] 1929b, p. 29). Juntamente às questões de caráter mais prático, voltadas para o atendimento dos pacientes, Porto-Carrero se preocupava também com os aspectos teóricos e com a formulação de um programa para a psicanálise dentro da Liga. De acordo com ele, tal programa poderia ser estabelecido da seguinte forma:

a) psicanálise nas escolas: será necessário ensinar a psicanálise às professoras primárias. A educação sexual, que nem sempre pode ser feita no lar, pode ser feita na escola; b) psicanálise dos menores contraventores e criminosos: a assistência psicanalítica, junto ao Juizado de Menores, seria sobremodo útil para a correção desses pequenos infelizes; c) educação pela psicanálise: o jornal e o radiofônico são veículos excelentes para a educação sexual da massa pela psicanálise; d) psicanálise dos toxicômanos, dos pervertidos sexuais, dos suicidas frustrados, dos neuróticos, em geral: uma pesquisa nos noticiários dos jornais poderia nos dar fundamentos para que esses numerosos infelizes fossem encaminhados ao consultório da Liga; e) aproveitamento do laboratório de psicologia experimental da Liga: para a sua aplicação à psicanálise e para encaminhar ao consultório os casos convenientes (Porto-Carrero, [1926] 1929b, p. 39-40).

Assim, com um programa instituído e com o consultório em funcionamento, começava a existir uma crescente relevância da psicanálise também nos espaços teóricos da Liga. Conforme republicação de seu Estatuto em 1929, a Liga já havia acrescido mais objetivos a sua atuação e já havia reorganizado suas "Seções de Estudo", que eram mantidas com o objetivo de preparar e pôr em prática seus desígnios. Além de "organizar um arquivo tão completo quanto possível sobre questões de higiene mental” (Estatutos, 1929, p. 40), a Liga passava a ter como objetivo "promover o estudo e desenvolvimento dos novos processos de psicologia aplicada e da psicanálise" (Estatutos, 1929, p. 40).

No ano de 1929, na republicação dos seus estatutos, aparecia de fato a seção de estudo intitulada "Psicologia aplicada e psicanálise". A configuração da seção indicava uma evidente relação que se pretendia estabelecer entre tais temas e a educação. Em primeiro lugar, seu presidente era Manoel Bonfim (1868-1932), professor catedrático de psicologia da Escola Normal do Rio de Janeiro. Conforme ressaltado pelo historiador André Botelho, o diagnóstico realizado por Manoel Bonfim quanto aos males de origem do Brasil e dos brasileiros apontava para uma "transformação estrutural da sociedade por meio da educação, recusando-se o 'racismo científico' e apontando o papel da educação como fator determinante para contrapor as teses deterministas fundadas nos dogmas da hierarquia natural 
entre homens e nações" (Botelho, 2009, p. 126). Além de Bonfim, os outros membros da seção tinham ligação direta com a educação, nos mais diferentes níveis: o vice-presidente era o missionário e professor C. A. Baker (?) - professor de metodologia do Colégio Batista - e outro membro era o professor Dr. Plínio Olinto (1886-1956) - psiquiatra-chefe do Serviço de Assistência a Psicopatas do Hospício Nacional, chefe do Serviço de Profilaxia Mental do Ambulatório Rivadávia Correa e docente de psicologia na Escola Normal. A seção era composta, ainda, por professoras e "senhoras" da sociedade carioca. A secretária era a professora municipal Dona Nicolar Cortat Frossard, que chegou a publicar nos Arquivos Brasileiros de Higiene Mental ${ }^{14}$ um artigo dedicado aos "tests de Binet em nossos escolares" (Frossard, 1930). Além dela, faziam parte a senhora Lúcia Fernando Magalhães (da Associação Brasileira de Educação) e as professoras Maria Brasília Leme Lopes (professora municipal) e Idalina de Abreu Fialho (professora do Instituto Benjamin Constant) (Estatutos, 1929, p. 55). As duas últimas publicaram em coautoria o artigo "Sugestões para o emprego dos tests", no ano de 1929, também nos arquivos da Liga (Lopes, Fialho, 1929).

A constituição dessa seção de estudos era pensada para que fosse possível à Liga penetrar no meio educacional, via professores e gestores escolares. O que também chamava atenção, além da própria configuração da seção, era o fato de Porto-Carrero declarar que um dos principais objetivos dos interessados pela psicanálise da Liga era oferecer lições sobre esse saber aos educadores e aos pais. Especialmente, o autor apresentava a educação sexual como um dos itens mais importantes que deviam nortear tanto a educação das crianças quanto a educação dos pais e professores, por representar o núcleo da ação voltada para a profilaxia de neuroses e anomalias diversas. Por isso ele chamava a atenção para a necessidade de pôr fim à "arte de perverter" (Porto-Carrero, 1929a), que derivava dos ensinamentos de professores e pais que ignoravam ou se mostravam incapazes de assimilar os conhecimentos pedagógicos de forma geral e os psicanalíticos, em especial. Conforme ressaltava Porto-Carrero, a "obra dos professores deve começar pela educação dos pais, que se faz diretamente pelos círculos de pais e mestres ou indiretamente, por via do próprio aluno" (Porto-Carrero, 1930, p. 6).

O discurso de Porto-Carrero para persuadir os professores e intensificar as investidas da Liga no meio educacional se tornava, também, cada vez mais evidente: "já não há doenças vergonhosas: há perigos a evitar. Falareis melhor do que o médico, que não é mestre, que não ama vossos discípulos com o carinho que lhes dedicais [...]. O currículo do ensino está nas vossas mãos" (Porto-Carrero, 1929c, p. 131). Diante de tantas e tão complexas questões,

${ }^{14}$ Órgão oficial e periódico dedicado, entre outros, à divulgação dos trabalhos desenvolvidos pela Liga, começou a ser publicado em 1925. Porém, devido ao corte da subvenção federal, ficou três anos fora de circulação, retornando em 1929. Manteve-se regular até 1935, interrompendo-se de novo em 1936-1937 e voltando à cena entre 1938 e 1947 (Reis, 1994, p. 118). 
era preciso fazer com que a psicanálise não permanecesse institucionalizada exclusivamente dentro da Liga Brasileira de Higiene Mental. Nesse sentido, o passo seguinte na busca pela sistematização de tal saber e sua inserção no meio científico nacional foi buscar o apoio institucional de um espaço adequado para o debate acadêmico, voltado unicamente para a questão educacional: a Associação Brasileira de Educação (Castro, 2016).

\section{Considerações finais}

Conforme procuramos mostrar, a psicanálise foi apropriada por um grupo de psiquiatras como uma importante ferramenta para trazer novas respostas ao problema da identidade nacional. Para tanto, eles consideravam necessário fazer da ferramenta psicanalítica uma prática científica institucionalizada, organizando, por exemplo, a Clínica de Psicanálise dentro da Liga Brasileira de Higiene Mental. Nesse espaço foi possível organizar toda uma "metapsicologia ortopédica" para instruir os brasileiros a moldarem seus comportamentos, educarem seus filhos e aprenderem como "descarregar" seus impulsos no ambiente com o mínimo de prejuízo para a sociedade (e, de preferência, em seu benefício).

A leitura da psicanálise possibilitava que se definisse a intervenção desses psiquiatras-psicanalistas através, principalmente, da "educação dos impulsos" do sujeito. Essa orientação quanto a melhor forma de "descarga dos impulsos" teve como foco evitar o aparecimento de estados patológicos (principalmente nas crianças), moldar o comportamento em situações onde já fosse possível identificar desvios (através de uma reeducação dos impulsos, da correção dos "maus hábitos") e educar os já "degenerados" (pessoas que manifestavam excessos e comportamentos desviantes - principalmente sexuais -, criminosos, alcoólatras, dentre outros) para que não causassem maiores danos à sociedade (Castro, 2015).

Essa seria, portanto, a especificidade do projeto dos psiquiatras leitores da psicanálise para modernizar e "regenerar" a "identidade nacional". Se ao brasileiro faltava iniciativa e ideais a seguir; se sua sexualidade exacerbada era reflexo de seu comportamento "primitivo"; se a prostituição, o crime, as doenças venéreas e taras degenerativas estavam presentes na maioria do território brasileiro (Porto-Carrero, 1933); os psiquiatras, com auxílio da ferramenta psicanalítica, poderiam intervir: era necessário educar o brasileiro, fazendo evoluir seu "id", moldando seu "ego" à civilização (Castro, 2015). Tal psicodiagnóstico tornava-o apto a receber o projeto que então se propunha: se as manifestações comportamentais brutas, sem controle e/ou condução, eram consequência do primitivismo dos brasileiros, era preciso combater as degenerações provenientes de seu abandono pelo Estado e pela educação familiar e da escola, através da implementação de condições educativas favoráveis ao seu desenvolvimento "interior", da "civilização" de seu ego. 


\section{Referências}

ALMEIDA, Rafael Gonçalves. A emergência da favela como objeto da prática médica. Terra Brasilis (Rio de Janeiro). v. 8, p. 1-19, 2017.

BENCHIMOL, Jaime L. Pereira Passos: um Hausmann Tropical: a renovação urbana na cidade do Rio de Janeiro no início do século XX. Rio de Janeiro: Secretaria Municipal de Cultura, Turismo e Esportes, 1992.

BENCHIMOL, Jaime L. A instituição da microbiologia e a história da saúde pública no Brasil. Ciência eSaúde Coletiva (Rio de Janeiro). v. 5, n. 2, p. 265-293, 2000.

BERTOLOTE, José M. Raíces del concepto de salud mental. World Psychiatry. n. 7, p. 113-116, 2008. Disponível em: 〈https://pt.slideshare.net/titovitor/races-del-concepto-de-salud-mental . Acesso em: 26 mar. 2020.

BERTUCCI, Liane. Limpar, medicar e educar: considerações sobre a saúde pública em Curitiba nas primeiras décadas do período republicano. Resgate (Campinas). v. 27, n. 2, p. 49-70, 2019.

BOARINI, Maria L. Higienismo, eugenia e a naturalização do social. In: BOARINI, Maria L. (org.). Higiene e raça como projetos: higienismo e eugenismo no Brasil. Maringá: Eduem, 2003, p. 19-43.

BOTELHO, André. Manoel Bonfim: um percurso da cidadania no Brasil. In: BOTELHO, André; SCHWARCZ, Lilia. (orgs.). Um enigma chamado Brasil: 29 intérpretes e um país. São Paulo: Companhia das Letras, 2009, p. 118-131.

BRASIL. Decreto n. 1.132, de 22 de dezembro de 1903. Organiza a Assistência a Alienados. Disponível em: 〈https://www2.camara.leg.br/legin/fed/decret/19001909/decreto-1132-22-dezembro-1903-585004-publicacaooriginal-107902-pl.html〉. Acesso em: 24 mar. 2020.

BRASIL. Decreto n. 5.148-A, de 10 de janeiro de 1927. Reorganiza a Assistência a Psicopatas no Distrito Federal. Disponível em: 〈https:/www2.camara.leg.br/ legin/fed/decret/1920-1929/decreto-5148-a-10-janeiro-1927-563139-publicacaooriginal-87269-pl.html>. Acesso em: 24 mar. 2020.
BRESCIANI, Maria Stella. O charme da ciência e a sedução da objetividade: Oliveira Vianna entre intérpretes do Brasil. São Paulo: EdUnesp, 2007.

CASTRO, Rafael. Psicanálise e educação sexual na obra de Julio Porto-Carrero: Rio de Janeiro (décadas de 1920 e 1930). In: MOLLO, Helena Miranda (org.). Biografia e história das ciências: debates com a história da historiografia. Ouro Preto: EdUfop, 2012, v. 1, p. 185-202.

CASTRO, Rafael. A sublimação do id primitivo em ego civilizado: o projeto dos psiquiatras-psicanalistas para civilizar o país, 1926-1944. Jundiaí: Paco, 2015.

CASTRO, Rafael. A Associação Brasileira de Educação e a inserção da psicanálise no campo educacional: Julio Porto-Carrero, Pedro Deodato de Moraes e Renato Jardim (1927-1931). Revista HistedBR On-line, v. 16, p. 89-108, 2016.

CASTRO-SANTOS, Luiz Antônio de. O pensamento sanitarista na Primeira República: uma ideologia de construção nacional. Dados (Rio de Janeiro). v. 28, n.2, p. 193-210, 1985.

CUPELLO, Priscila C. A mulher (a)normal: representações do feminino em periódicos científicos e revistas leigas na cidade do Rio de Janeiro (1925-1933). Dissertação (Mestrado em História das Ciências e da Saúde), Casa de Oswaldo Cruz, Fiocruz. Rio de Janeiro, 2013.

DAGFAL, Alejandro. Para una "estética de la recepción” de las ideas psicológicas. Frenia. v. 4, n. 2, p. 7-16, 2004.

EDLER, Flávio C. O debate em torno da medicina experimental no Segundo Reinado. História, Ciências, Saúde - Manguinhos (Rio de Janeiro). v. 3, n.2, p. 284 299. 1996.

ENGEL, Magali G. Os delírios da razão: médicos, loucos e hospícios (Rio de Janeiro, 1830-1930). Rio de Janeiro: Editora Fiocruz, 2001.

ESTATUTOS da Liga Brasileira de Higiene Mental. Arquivos Brasileiros de Higiene Mental (Rio de Janeiro). ano 1, n. 1, 1925, p. 223-234.

ESTATUTOS da Liga Brasileira de Higiene Mental. 
Arquivos Brasileiros de Higiene Mental (Rio de Janeiro). ano 2, n. 1, 1929, p. 39-56.

FACCHINETTI, Cristiana. Deglutindo Freud: história da digestão do discurso psicanalítico no Brasil, 1920-1940. Tese (Doutorado em Teoria Psicanalítica), Universidade Federal do Rio de Janeiro. Rio de Janeiro, 2001.

FACCHINETTI, Cristiana; CASTRO, Rafael. Die Psychoanalyse als psychiatrisches Werkzeug: Die Rolle Juliano Moreira (1900-1930). In: SANTOSSTUBBE, Chirly dos; THEISS-ABENDROTH, Peter; STUBBE, Hannes (orgs.). Psychoanalyse in Brasilien: Historische und aktuelle Erkundungen. Gießen: Psychosozial-Verlag, 2015, p. 85-112.

FACCHINETTI, Cristiana; MUÑOZ, Pedro N. Emil Kraepelin na ciência psiquiátrica do Rio de Janeiro, 1903-1933. História, Ciências, Saúde - Manguinhos (Rio de Janeiro). v.20, n.1, p. 239-262, 2013.

FROSSARD, Nicolar Cortat. Os tests de Binet em nossos escolares. Arquivos Brasileiros de Higiene Mental (Rio de Janeiro). ano 3, n. 4, p. 127-131, 1930.

GARMANY, Jeff; RICHMOND, Matthew. Hygienisation, gentrification, and urban displacement in Brazil. Antipode, v. 52, n. 1, p. 124-144, 2020. Disponível em: 〈https://onlinelibrary.wiley.com/doi/pdf/ 10.1111/anti.12584〉. Acesso em: 29 jun. 2020.

GLICK, Thomas. Precursores del psicoanálisis en América Latina. Episteme: Filosofia e História das Ciências em Revista (Porto Alegre). n. 8, p. 139-150, jan.-jun. 1999.

GUMBRECHT, Hans Ulrich. Sobre os interesses cognitivos, terminologia básica e métodos de uma ciência da literatura fundada na teoria da ação. In: LIMA, Luiz C. A literatura e o leitor: textos de estética da recepção. Rio de Janeiro: Paz e Terra, 2001.

HOCHMAN, Gilberto. A era do saneamento: as bases da política de saúde pública no Brasil. São Paulo: Hucitec/ Anpocs, 1998.

LIMA, Nísia T. Um sertão chamado Brasil. Rio de Janeiro: Renavan/Iuperj, 1999.

LIMA, Nísia; HOCHMAN, Gilberto. Condenados pela raça, absolvidos pela medicina: o Brasil descoberto pelo movimento sanitarista da Primeira Repú- blica. In: MAIO, Marcos Chor; SANTOS, Ricardo Ventura (orgs.). Raça, ciência e sociedade. Rio de Janeiro: Fiocruz/CCBB, 1996, p. 23-40.

LIMA, Nísia T.; HOCHMAN, Gilberto. Pouca saúde e muita saúva: sanitarismo, interpretações do país e ciências sociais. In: HOCHMAN, Gilberto; ARMUS, Diego (orgs.). Cuidar, controlar, curar: ensaios históricos sobre saúde e doença na América Latina e Caribe. Rio de Janeiro: Editora Fiocruz, 2000, p. 313-332.

LOPES, Maria Brasília Leme.; FIALHO, Idalina. Sugestões para o emprego dos tests. Arquivos Brasileiros de Higiene Mental (Rio de Janeiro). ano 2, n. 1, p. 68-77, 1929.

MAIO, Marcos Chor; SANTOS, Ricardo Ventura (orgs.). Raça como questão: história, ciência e identidades no Brasil. Rio de Janeiro: Editora Fiocruz, 2010.

MOREIRA, Juliano. Notícia sobre a evolução da assistência a alienados no Brasil e reformas efetuadas no Hospício de Alienados no Rio de Janeiro. Archivos Brasileiros de Psychiatria, Neurologia e Sciencias Affins (Rio de Janeiro). ano l, n.l, p. 52-98, 1905.

MOREIRA, Juliano. A luta contra as degenerações nervosas e mentais no Brasil (comunicação apresentada no Congresso Nacional dos Práticos). Brasil Médico (Rio de Janeiro). ano 2, p. 225-226, 1922.

MOREIRA, Juliano; PEIXOTO, Afrânio. Les maladies mentales dans les climats tropicaux. Archivos Brasileiros de Psychiatria, Neurologia e Sciencias Affins (Rio de Janeiro). ano 2, n. 1, p. 222-241, 1906.

ODA, Ana. Alienação mental e raça: a psicopatologia comparada dos negros e mestiços brasileiros na obra de Raimundo Nina Rodrigues. Tese (Doutorado em Ciências Médicas), Universidade Estadual de Campinas. Campinas, 2003.

PLOTKIN, Mariano. Psicoanálisis y habitus nacional: un enfoque comparativo de la recepción del psicoanálisis en Argentina y Brasil (1910-1950). Memoria y Sociedad, v. 13, n. 27, p. 61-85, 2009.

PORTO-CARRERO, Julio. A arte de perverter: aplicação psicanalítica à formação moral da criança. In: PORTO-CARRERO, Julio. Ensaios de psicanálise. Rio de Janeiro: Flores e Mano, 1929a, p. 133-142. 
PORTO-CARRERO, Julio. A psicanálise na Liga Brasileira de Higiene Mental In: PORTO-CARRERO, Julio. Ensaios de psicanálise. Rio de Janeiro: Flores e Mano, [1926] 1929b, p. 27-40.

PORTO-CARRERO, Julio. Educação sexual. Arquivos Brasileiros de Higiene Mental (Rio de Janeiro). ano II, n. 3, p. 120-133, dez. 1929c.

PORTO-CARRERO, Julio. Resposta de um especialista ao inquérito sobre Educação Sexual. Boletim de Eugenia (Rio de Janeiro). ano 2, n. 24, p. 5-6, dez. 1930. PORTO-CARRERO, Julio. Sexo e cultura. Rio de Janeiro: Guanabara, Waissman, Koogan, 1933.

RAJ, Kapil. Conexões, cruzamentos, circulações: a passagem da cartografia britânica pela Índia, séculos XVII-XIX. Trad. Catarina Santos. Cultura (Lisboa). v. 24, p. 155-179, 2007.

REIS, José. Higiene mental e eugenia: o projeto de "regeneração nacional" da Liga Brasileira de Higiene Mental (19201930). Dissertação (Mestrado em História), Universidade Estadual de Campinas. Campinas, 1994.

RUPERTHUZ, Mariano. "Freud para todos": psicoanálisis y cultura de masas en Chile, 1920-1950. História, Ciências, Saúde - Manguinhos (Rio de Janeiro). v. 24, supl., p. 121-141, 2017.

RUSSO, Jane. A psicanálise enquanto processo civi- lizador: um projeto para a nação brasileira. Cadernos Ipub (Rio de Janeiro). v. 16, n. 18, p. 10-20, 2000.

SÁ, Dominichi Miranda de. A voz do Brasil: Miguel Pereira e o discurso sobre o "imenso hospital". História, Ciências, Saúde-Manguinhos (Rio de Janeiro). v.16, supl., p. 333-348, 2009.

SEVCENKO, Nicolau. A revolta da vacina: mentes insanas em corpos rebeldes. São Paulo: Brasiliense, 1984.

SOUZA, Vanderlei Sebastião de. A política biológica como projeto: a "eugenia negativa" e a construção da nacionalidade na trajetória de Renato Kehl (1917-1932). Dissertação (Mestrado em História das Ciências e da Saúde), Casa de Oswaldo Cruz, Fiocruz. Rio de Janeiro, 2006.

STARLING, Heloisa. A República e o sertão: imaginação literária e republicanismo no Brasil. Revista Crítica de Ciências Sociais (Coimbra). n. 82, p. 133-147, 2008.

VENANCIO, Ana. Ciência psiquiátrica e política assistencial: a criação do Instituto de Psiquiatria da Universidade do Brasil. História, Ciências, Saúde-Manguinhos (Rio de Janeiro). v. 10, n.3, p. 883-900, 2003.

VENANCIO, Ana; FACCHINETTI, Cristiana. Gentes provindas de outras terras: ciência psiquiátrica, imigração e nação brasileira. Revista Latinoamericana de Psicopatologia Fundamental (São Paulo). v. VIII, n. 2, p. $356-364,2005$. 